Preprint of: Scott, G.G., \& Fullwood. C. (2020). Does recent research evidence support the hyperpersonal model of online impression management? Current Opinion in Psychology, 36, 106111.

\title{
Does recent research evidence support the hyperpersonal model of online impression management? \\ Graham G. Scott ${ }^{1 *}$ and Chris Fullwood ${ }^{2}$
}

${ }^{1}$ University of the West of Scotland, School of Education and Social Sciences

${ }^{2}$ University of Wolverhampton, Department of Psychology

*Corresponding author: Dr Graham Scott

Division of Social Work \& Psychology

School of Education and Social Sciences

University of the West of Scotland

Paisley

United Kingdom

Email: graham.scott@uws.ac.uk 


\section{Abstract}

The hyperpersonal mode of communication was conceived in the 1990s and has driven much of the research into online impression management. It is based on four principal tenets (increased control, asynchronicity of communication, increased physical distance, increased cognitive resources) and has largely been supported, especially by research involving text-only communication. This review briefly summarises this research before identifying four areas in which it is not supported by findings: use of language in online environments, online self-disclosure, the expanding nature of online platforms to include pictures and video, and the wider context of online communication. We suggest that the model is modified and updated, or its limitations defined, with respect to this evidence.

\section{Introduction}

Two distinct perspectives characterise the social and communicative repercussions of interacting via less 'rich' forms of media, i.e. those less able to handle multiple information cues concurrently [1]. This includes many forms of computer-mediated communication (CMC), such as e-mail and instantmessaging (e.g. WhatsApp), as they limit access to nonverbal communication (NVC) and social cues $[2,3]$. What might be labelled collectively as the 'cues-filtered out' perspectives $[4,5]$ assume that NVC is important in human interaction as they increase our capacity to interpret the affective experiences of others and therefore reduce ambiguity in communication [3], but also help people garner more positive impressions from others $[2,3,6,7]$. Thus, platforms which restrict access to NVC may be less effective for certain types of interactions, e.g. those which rely on making accurate impressions of others $[3,5,6]$ and result in low social presence $[4,8,9,10]$.

In direct opposition to these perspectives, Joseph Walther proposed the Hyperpersonal model. Rather than thinking about what is 'lost' from $\mathrm{CMC}$, Hyperpersonal theory centres on the benefits accrued from the attenuation of social and communication cues, focusing on the various affordances such modes of communication grant users. These affordances permit communicators to 
engage in strategic impression management to convey 'optimal' self-presentations, which may in turn lead to favourable outcomes for the individual [11,12].

\section{The basic tenets of Hyperpersonal model}

According to Hyperpersonal theory there are four idiosyncratic features of $\mathrm{CMC}$ which may enhance self-presentation [11,12]. First, users can exert greater control over how they present the self in CMC compared to face-to-face. This is especially true on social media sites like Facebook since the advent of Web 2.0 technologies enable individuals to choose and edit content to represent specific desirable self-images $[13,14]$.

The second affordance concerns the notion that many forms of $\mathrm{CMC}$ do not take place in real time. Even in cases where users might assume synchronicity (e.g. instant messaging), an artefact of text-based $\mathrm{CMC}$ is that communicators decide when to send messages in full, depriving receivers access while it is being is formulated [13]. An advantage of asynchronous communication is the ability to reflect on what and how one communicates, so as to come across in the most desired way $[11,12]$

The third affordance discusses the absence of physical proximity to one's co-communicator. Not being in the same co-present location means that undesirable communication cues which we may wish to hide, e.g. blushing, are invisible to others. The resulting reduction in concern about receiving negative judgements frees users up to accentuate images they wish to convey $[11,12]$.

The final affordance proposes that we can make more effective use of our cognitive resources in CMC. Walther argues that paying attention to others' NVB, in addition to attending to environmental cues and engaging in self-monitoring, can be cognitively demanding. Thus, when we remove these competing, and potentially distracting, cues from communication, we can concentrate our efforts into the sole task of presenting the self optimally [11,12]. 


\section{Evidence supporting Hyperpersonal theory}

Evidence supporting Hyperpersonal theory's utility to explain different online behaviours comes in the form of self-report, observational and experimental data, thus providing assurances of the validity of the model through data triangulation. When given the option of how to communicate a socially risky message, e.g. asking for a pay raise, lower self-esteem individuals preferred email to face-to-face [15]. This might be because they can control for the communication of negative social cues because of a lack of physical proximity, but also compensate for having less self-confidence through an ability to edit messages to perfection, due to asynchronicity. Lower self-concept clarity [16], which has been associated with lower self-esteem, has also been linked to a preference for managing impressions online [17].

Further evidence to support these ideas comes from Fullwood and Attrill [18] who found that participants believed they would have more success attracting others to agree to go on a date with them if they were interacting online rather than offline. Evidence suggests that a greater level of editability of one's self-image on social media sites may lead to the belief that our profile portrays us as superior to the 'offline' reality on dimensions including humour and a sense of adventure [19]. Moreover, Antheunis et al. [20] found that dyads who had initially communicated in a more cuerestricted context $(\mathrm{CMC})$ reported higher levels of social attraction with their communication partners face-to-face compared to dyads who had met first in a more cue-rich context (videoconferencing). Thus, evidence demonstrates that not only do people consider their own online self to be superior to their offline self, but others also seems to rate them more positively.

Observational data in the form of comparisons of different communication modalities of varying levels of richness, demonstrate that individuals ask more questions and disclose more personal information when communicating via text-only $\mathrm{CMC}$ in comparison to video-mediated and face-to-face communication. Moreover, this was also said to have enhanced interpersonal attraction between the communicators [21]. These data may be interpreted as communicators feeling more comfortable communicating in the way that they desired because of the affordances granted by the 
technology. Indeed, the affordance of asynchronicity has been shown to lead to more selfenhancement (e.g. discussing more interesting information) in comparison to synchronous communicators [22].

Finally, experimental evidence from Duthler [23] found that independent judges rated student requests to University professors for a meeting as more polite when these were communicated over email rather than voicemail. The authors argue that the asynchronous nature of emails provided communicators with a greater potential to consider how their request might be received, time to plan their message and edit it so they would be more likely to be perceived favourably. Furthermore, students were perceived more favourably via email even when they were making requests to meet outside of the professor's normal scheduled office hours.

\section{Evidence against Hyperpersonal theory}

While the evidence above supports the hyperpersonal model, other evidence highlights its limitations. These will be outlined below, focusing firstly on the language used in CMC, secondly considering the implications of research into online self-disclosure, and thirdly looking at the expanding nature of $\mathrm{CMC}$ to include photo and video communication, and the impact of this on a traditionally text-only theory. Finally, we will consider the context of communication on social media taking into account other evidence available to communication recipients forming impressions, including pre-conceived bias such as gender stereotypes.

Despite the asynchronicity of message sending communicators often formulate messages which lead to negative impressions. Accommodation in word use is a natural phenomenon and can increase positivity of impressions in both on and offline contexts $[24,25]$. However, online accommodation on the part of higher-powered towards lower-powered communication partners led to more negative impressions being formed [26]. In online environments use of unstandardized language is also normal [27]. Use of textspeak persists online today [28], but text-speak can lead to lower perceived conscientiousness [29] and lower perceived intelligence, competence and 
employability, with no increase in social-, physical-, or task-attractiveness [30]. Language errors occur often online and on dating sites negatively impact ratings of social and romantic attractiveness and intelligence [31].

A prediction of the hyperpersonal model is that online (vs. face-to-face) communication leads to greater intimacy, and hence increased depth and breadth of self-disclosure [32,33]. It has been observed that while experimental findings often support the hyperpersonal model by reporting increased self-disclosure in CMC vs. face-to-face environments, this is not always the case [34] and the same pattern is not found in survey-based research [35]. Although one 2012 literature review found support for the hyperpersonal model in more depth of self-disclosures in $\mathrm{CMC}$, the same effect was absent for breadth of self-disclosures [36]. Two meta-analyses also examined this. One found no difference in self-disclosure in CMC vs face-to-face [37]. The other not only found greater self-disclosure in face-to-face, but that this was greater for depth (vs. breadth) of self-disclosure, and greater self-disclosure occurred in video-CMC vs. text-CMC communications. These findings oppose the assumption that greater intimacy will be built in text-based communications, although this second analysis noted that many of the relationships examined were both pre-existing and multimodal [35]. Increased self-disclosure also results in increased attributed victim blame in cases of cyberbullying [38].

The increasing photographic content online, particularly on social media, goes against what was traditionally a text-only model of communication. Users are often unaware how photos are perceived and thus cannot use them to positively self-present: on Air B\&B multi-person photos promote trustworthiness but are utilized by only $13 \%$ of users [39]. Many individuals post selfies to try and positively self-present [40] but Facebook users who do so are viewed as less trustworthy, socially attractive, open, and more narcissistic than these depicted in photos taken by others [41]. Video is also being increasingly used for online communication, and users utilize text, audio, and video communication simultaneously [42]. This reintroduces synchronicity and many non-verbal cues, the absence of which were the basis of the hyperpersonal model. Contrary to the model's 
predictions participants interacting face-to-face report more liking, closeness, and enjoyment, and lower conflict towards their partner than those interacting via CMC-text. Participants interacting in a getting to know you exercise face-to-face experienced greater enjoyment, liking, and closeness than those interacting via CMC-text $[34,43]$. Sprecher [44] had participant pairs engage in two interactions. The second was always CMC-video (Skype), the first could be SMS text, CMC audio, $\mathrm{CMC}$ video, or face-to-face. After the first interaction CMC-text pairs scored lower on liking than the others, but they 'caught up' after the second interaction. Impression management in video calls is dependent on the communication partner, with qualitative evidence showing that individuals engaging in more scene-setting and presentation related to their personal appearance when talking to friends, colleagues, and acquaintances, rather than friends or close family [45].

The hyperpersonal model was initially devised as a way of explaining impression management in text-only communications but social media often includes information produced by third parties as well as the primary communicator. The hyperpersonal model only applies without the presence of contradictory information, specifically that present on social media pages, which can lead to reduced liking and increased uncertainty [46]. Warranting theory [47] states that when forming impressions observers rely on identity claims (overt claims by the communicator) and behavioural residue (unintentional information, including third party content online). Both influence impressions formed of communicators, and while identity claims can be manipulated to enhance impression management, observers are aware of this and thus attribute more weight to behavioural residue [48]. Personality judgments based on Facebook profiles are generally accurate, despite users' attempts to positively manage their self-presentation [49].

When the valence of the language used on Facebook was manipulated, positive language in author-generated posts (identity claims) resulted in higher ratings of physical and social attractiveness, but task-attractiveness was increased by other-generated content [50]. A separate study found that identity claims impacted perceived confidence, but behavioural residue increased perceived modesty and popularity [51]. Similarly, while ICs positively impacted cognitive and 
structural social capital, relational capital was only influenced by behavioural residue [52]. Content generated by third parties also impact the blame attributed to victims of online abuse such as cyberbullying, and the perceived severity of observed incidents. One study which examined perceptions of abuse on Facebook showed the behavioural residue (the volume and source(s) of abuse) influenced the amount of blame attributed to the victim [53].

While individuals may be able to control the information they convey online, how that information is processed by the receiver, and observers, is subject to innate biases such as gender stereotypes. Male Facebook profile owners are rated as more narcissistic and less trustworthy than female profile owners [41]. Women view insensitive messages received from other women especially negatively online versus face-to-face [54]. Third party accounts of heavy drinking and promiscuous behaviour on Facebook result in positive perceptions of male profile owners, but negative perceptions of females [55]. Analyses show differences in viewing strategy when looking at male vs female Facebook timelines, meaning that depending on gender different cues will be prioritised by viewers, and this is outside the control of the timeline owner [56]. The website on which a photo is presented can also influence perceptions. Physicians were rated more negatively when they presented casual vs. professional pictures on WebMD, but a different pattern was shown for Facebook, suggesting a knowledge of normative website expectations can lead to positive or negative evaluations [57].

\section{Conclusions}

The hyperpersonal model of online impression management was first hypothesized over two decades ago at a time when online communication meant two individuals communicating with each other in a text only online bubble. Despite the advances in technology, most notably the advent of web 2.0 technology and the rise of the Internet as we know it today, the tenets of the model still hold true in many situations, but the evidence outlined above demonstrated that aspects of the theory may need modified to account for new technology, or the limits of the model in the new 
online environment need to be more clearly delineated. In particular, where the bubble bursts and information from several sources (some of which may be incongruous to the primary communicator's identy claims) are available, and where communication mediums are richer than text-only (e.g., pictures and video communication on social media), are where research findings seem to diverge with the predictions of the original model.

\section{References}

[1] Daft RL, Lengel RH: Organizational information requirements, media richness and structural design. Management Science 1986, 32:554-571.

[2] Kato $\mathrm{Y}$, Kato S, Akahori K: Effects of emotional cues transmitted in e-mail communication on the emotions experienced by senders and receivers. Computers in Human Behavior 2007, 23(4):18941905.

[3] Tanis M, Postmes T: Social cues and impression formation in CMC. Journal of Communication 2003, 53(4):676-693.

[4] Short J, Williams E, Christie B. The Social Psychology of Telecommunications. Wiley \& Sons; 1976.

[5] Culnan MJ \& Markus ML: Information technologies. In Handbook of Organizational Communication: An Interdisciplinary Perspective . Edited by Jablin FM, Putnam LL, Roberts KH, \& Porter LW. Sage; 1987:420-443.

[6] Fullwood C: The effect of mediation on impression formation: A comparison of face-to-face and video-mediated conditions. Applied Ergonomics 2007, 38(3):267-273.

[7] Hancock JT, Dunham PJ: Impression formation in computer-mediated communication revisited: An analysis of the breadth and intensity of impressions. Communication Research 2001, 28(3):325347. 
[8] Croes EA, Antheunis ML, Schouten AP, Krahmer EJ: Teasing apart the effect of visibility and physical co-presence to examine the effect of $\mathrm{CMC}$ on interpersonal attraction. Computers in Human Behavior 2016, 55:468-476.

[9] Liebman, N, Gergle D: It's (Not) simply a matter of time: The relationship between CMC cues and interpersonal affinity. In Proceedings of the 19th ACM conference on computer-supported cooperative work \& social computing 2016. 570-581.

[10] Rice RE, Case D: Electronic message systems in the university: A description of use and utility. Journal of Communication 1983. 33(1):131-152. https://doi.org/10.1111/j.14602466.1983.tb02380.x

[11] Walther JB: Computer-mediated communication: impersonal, interpersonal, and hyperpersonal interaction. Communication Research 1996, 23:3-43.

[12] Walther JB: Selective self-presentation in computer-mediated communication: Hyperpersonal dimensions of technology, language, and cognition. Computers in Human Behavior 2007, 23(5):2538-2557.

[3] Fullwood C: Impression management and self-presentation online. In The Oxford Handbook of Cyberpsychology edited by Attrill-Smith A, Fullwood C, Keep M, Kuss D OUP; 2019:

[14] Turkle S: Reclaiming conversation: The power of talk in a digital age. Penguin; 2016.

[15] Joinson AN: Self-esteem, interpersonal risk, and preference for e-mail to face-to-face communication. CyberPsychology \& Behavior 2004, 7(4):472-478.

[16] Campbell JD, Trapnell PD, Heine SJ, Katz IM, Lavallee LF, Lehman DR: Self-concept clarity: Measurement, personality correlates, and cultural boundaries. Journal of personality and social psychology 1996, 70(1):141. 
*[17] Fullwood C, James BM, Chen-Wilson CH: Self-concept clarity and online self-presentation in adolescents. Cyberpsychology, Behavior, and Social Networking 2016, 19(12):716-720.

This study makes a unique contribution to knowledge by recognising that one's level of selfconcept clarity (i.e., the extent to which one has clear beliefs about who they are) has an important impact on how likely one is to present idealised and multiple self-presentations, and is further evidence for the notion that the online world can be used as a 'tool' to experiment with self-presentation as an act of self-discovery.

*[18] Fullwood C, Attrill A: Updating: Ratings of perceived dating success are better online. Cyberpsychology, Social Networking and Behavior 2018, 21(1):11-15.

This experimental study provides evidence, in a zero acquaintance dating context, for the notion that people assume that others will perceive their 'online' self-image as more desirable than their 'offline' one, perhaps as a consequence of a greater ability to edit images and manage impressions whilst online.

[19] Toma CL, Carlson CL: How do Facebook users believe they come across in their profiles?: A meta-perception approach to investigating Facebook self-presentation. Communication Research Reports 2015, 32(1):93-101.

*[20] Antheunis ML, Schouten AP, Walther JB: The hyperpersonal effect in online dating: effects of text-based CMC vs. videoconferencing before meeting face-to-face. Media Psychology 2019, 1-20. DOI: $\underline{10.1080 / 15213269.2019 .1648217}$

This study makes a unique contribution to our understanding of how initial meeting context can impact perceptions of social attraction, with evidence suggesting that meeting via 'leaner' modalities (e.g. text-based) can provide people with a greater propensity to tailor their self-presentation and to garner desirable self-images in the minds of others. 
[21] Antheunis ML, Valkenburg PM, Peter J: Computer-mediated communication and interpersonal attraction: An experimental test of two explanatory hypotheses. CyberPsychology \& Behavior $2007,10(6): 831-836$.

[22] Berger J, lyengar R: Communication channels and word of mouth: How the medium shapes the message. Journal of consumer research 2013, 40(3):567-579.

[23] Duthler KW The politeness of requests made via email and voicemail: Support for the hyperpersonal model. Journal of computer-mediated communication 2006, 11(2):500-521.

[24] Scissors LE, Gill AJ, Gergle D: Linguistic mimicry and trust in text-based CMC. In Proceedings of ACM 2008 conference on computer supported cooperative work.. ACM; 2008:277-280.

[25] Swaab RI, Maddux WW, Sinaceur M: Early words that work: When and how virtual linguistic mimicry facilitates negotiation outcomes. Journal of Experimental Social Psychology 2011, 47:616621.

[26] Muir K, Joinson A, Cotterill R, Dewdney N: Linguistic style accommodation shapes impression formation and rapport in computer-mediated communication. Journal of Language and Social Psychology 2017, 36(5):525-548. DOI: 10.1177/0261927X17701327

[27] Drouin MA. College students' text messaging, use of textese and literacy skills. Journal of Computer Assisted Learning 2011; 27:67-75.

[28] Thelwall M. MySpace Comments. Online Information Review 2009; 33:58-76.

[29] Fullwood C, Quinn S, Chen-Wilson J, Chadwick D, Reynolds K: Put on a smiley face: textspeak and personality perceptions. Cyberpsychology, Behavior, \& Social Networking 2015, 18(3): 147-51. doi: $10.1089 /$ cyber.2014.0463 
[30] Scott GG, Sinclair J, Short E, Bruce G: It's not what you say, it's how you say it: Language use on Facebook impacts employability but not attractiveness. Cyberpsychology, Behavior, \& Social Networking 2014, 17(8): 562-566. DOI: 10.1089/cyber.2013.0584

*[31] Van der Zanden T, Schouten AP, Moss MBJ, Khramer EJ: Impression formation on online dating sites: Effects of language errors in profile text on perceptions of profile owners' attractiveness. Journal of Social and Personal Relationships 2019, 37(3):758-778. DOI: $10.1177 / 0265407519878787$

This study found that on online dating sites, an environment where users acrefuly try to positively manage their impressions, language errors were common, and these negatively impacted on perceived romantic attractiveness and intelligence.

[32] Jiang LC, Barazova NN, Hancock JT: The disclosure-intimacy link in computer-mediated communication: An attributional extension of the hyperpersonal model. Human Communication Research 2011, 37:58-77. http://doi.org/10.1111/j.1468-2958.2010.01393.x

[33] Walther JB. Theories of computer-mediated communication and interpersonal relations. In The Sage Handbook of Interpersonal Communication Edited by Knapp ML, Daly JA. Sage; 2011:443479.

[34] Mallen MJ, Day SX, Green MA. Online versus face-to-face conversation: An examination of relational and discourse variables. Psychotherapy. Theory Research \& Practice 2003, 40(1-2):155163. DOI: $\underline{10.1037 / 0033-3204.40 .1-2.155}$

*[35] Ruppel EK, Gross C, Soll A, Peck BS, Allen M, Kim SY: Reflecting on connecting: Meta-analysis in differences between computer-mediated and face-to-face self-disclosure. Journal of ComputerMediated Communication 2015, 22:18-34. doi:10.1111/jcc4.12179 
A meta-analysis comparing online vs. offline self-disclosure which found greater selfdisclosure on video- than text-based communications, contrary to prediction of the hyperpersonal model.

[36] Nguyen M, Bin Y, Campbell A: Comparing online and offline self-disclosure: A systematic review. Cyberpsychology, Behavior, \& Social Networking 2012, 15:103-111.

http://doi.org/10.1089/cyber.2011.0277

[37] Kim J, Dindia K: Online self-disclosure: A review of research. In Computer-mediated communication in personal relationships Edited by Wright KB, Webb LM.Peter Lang Publishing; 2011:156-180.

[38] Weber M, Ziegele M, Schnauber: Blaming the victim: The effects of extraversion and information disclosure on guilt attributions in cyberbullying. Cyberpsychology, Behavior, and Social Networking 2013, 16(4):254-259.

[39] Ert E, Fleisher A: What do Airbnb hosts reveal by posting photographs online and how does it affect their perceived trustworthiness? Psychology and Marketing 2019, 37(5):1-11. DOI: 10.1002/mar.21297

[40] Katz JE, Crocker ET:. Selfie and photo messaging as visual conversation: reports from the United States, United Kingdom and China. Int. J. Commun 2015. 9:1861-1872.

[41] Kramer NC, Feurstein M, Kluck JP, Meier Y, Rother M, Winter S: Beware of selfies: The impact of photo type on impression formation based on social networking profiles. Frontiers in Psychology: Human-Media Interaction 2017, 8:article 188 doi: 10.3389/fpsyg.2017.00188

[42] Sumner EM, Ramirez AJR: Social Information Processing Theory and Hyperpersonal Perspective. In The International Encyclopedia of Media Effects Edited by Rössler P, Hoffner CA, Zoonen L. Wiley; 2017. doi:10.1002/9781118783764.wbieme0090 
[43] Okdie BM, Guadagno RE, Bernieri FJ, Geers AL, Mclarney-Vesotski AR: Getting to know you: Face-to-face versus online interactions. Computers in Human Behavior 2011, 27:153-159. doi:10.1016/j.chb.2010.07.017

[44] Sprecher S: Initial interactions online-text, online-audio, online-video, or face-to-face: Effects of modality on liking, closeness, and other interpersonal outcomes. Computers in Human Behavior 2014, 31:190-197. http://dx.doi.org/10.1016/j.chb.2013.10.029

*[45] Palupi P: Selective Self-Presentation Through Video-Mediated Communication: A Study of Hyperpersonal Communication. MediaTor 2019, 12(1):102-112.

Qualitative study which demonstrated that when communicating online individuals often engage in different levels of positive impression management, and that this is minimized when conversing with close friends or family members.

*[46] Paul A, Morrison K: Does your Facebook profle help or harm you? Examining the effect of information seeking strategies on relational outcomes in social networking sites. .Journal of Communication Technology and Human Behaviors 2017, 3(1):1-23. doi: 10.7726/jcthb.2017.1001 Demonstrates that contradictory information online leads to uncertainty, under which conditions the assumptions of the hyperpersonal model do not apply.

[47] Walther JB, Parks MR. Cues filtered out, cues filtered in: Computer-mediated communication and relationships. Handbook of interpersonal communication Edited by Knapp ML, Daly JA. Sage; 2002:529-563.

[48] Walther JB, Van Der Heide B, Hamel L, Shulman H: Self-generated versus other-generated statements and impressions in computer mediated communication: A test of warranting theory using Facebook. Communication Research 2009, 36:229-253.

[49] Wu T, Zheng Y: Is Impression Management Through Status Updates Successful? MetaAccuracy and Judgment Accuracy of Big Five Personality Traits Based on Status Updates From 
Social Network Sites in China. Frontiers in Psychology: Human Media Interaction 2019, 10:article 1192. doi: $10.3389 /$ fpsyg.2019.01192

[50] Rosenthal-Stott HES, Dicks RE, Fielding LS The Valence of Self-Generated (Status Updates) and Other-Generated (Wall-Posts) Information Determines Impression Formation on Facebook. PlosOne 2015. https://doi.org/10.1371/journal.pone.0125064

[51] Scott GG, Ravenscroft K: Bragging on Facebook: The interaction of content source and focus on online impression formation. Cyberpsychology, Behavior, \& Social Networking 2017, 20(1):58-63. doi: 10.1089/cyber.2016.0311

[52] Cummings J, Dennis AR: Virtual first impressions matter: The effect of enterprise social networking sites onimpression formation in virtual teams. MIS Quarterly 2018, 42(3):697-717. DOI: $10.25300 / \mathrm{MISQ} / 2018 / 13202$

[53] Scott GG, Wienercz S, Hand CJ: The frequency and source of online abuse impacts attribution of victim blame and perceptions of victim attractiveness. Computers in Human Behavior 2019, 92:119-127. https://doi.org/10.1016/i.chb.2018.10.037

[54] High AC, Solomon DH: Communication channel, sex, and the immediate and longitudinal outcomes of verbal person-centered support. Communication Monographs 2014, 81(4):439-468. doi: $10.1080 / 03637751.2014 .933245$

[55] Walther JB, Van Der Heide B, Kim SY, Westerman D and Tong ST: The role of friends' appearance and behavior on evaluations of individuals on Facebook: Are we known by the company we keep? Human Communication Research 2008, 34(1):28-49.

[56] Scott GG, Hand CJ: Motivation determines Facebook viewing strategy: An eye movement analysis. Computers in Human Behavior 2016, 56:267-280. 
[57] D'Angelo J, van der Heide B: The formation of physician impressions in online communities:

negativity, positivity, and nonnormtivity effects. Communication Research 2016, 43(1):49-72. DOI:

$10.1177 / 0093650213491112$ 